\title{
Virus Respiratorios en Menores de Diez Años con Infección Respiratoria en el Hospital Militar Central de Bogotá 2000-2001
}

\author{
Respiratory virus in children aged less than 10 years old suffering \\ from respiratory infection in the Hospital Militar Central in Bogota \\ from 2000-2001
}

\author{
Diana H. Herrera-Rodríguez ${ }^{1}$, Fernando de la $\mathrm{Hoz}^{2}$, \\ Cristina Mariño ${ }^{3}$ y Eliana Ramírez ${ }^{3}$
}

1 Grupo de virología, Instiuto Nacional de Salud. diana_herrerar@yahoo.es

2 Departamento de Salud Publica, Universidad Nacional de Colombia. fpdelahozr@unal.edu.co

3 Departamento de Pediatria. Hospital Militar Central, Bogota

Recibido 8 Agosto 2006/Enviado para Modificación 31 Marzo 2007/Aceptado 26 Agosto 2007

\section{RESUMEN}

Objetivo Se llevo a cabo un estudio en niños que consultaban por infección respiratoria aguda al Hospital Militar (Hosmil) de Bogota, Colombia, con el objetivo de estimar la frecuencia de enfermedad respiratoria aguda en esa institución producida por algunos virus respiratorios.

Métodos Durante 18 meses, de Marzo de 2000 a Septiembre de 2001, se seleccionaron semanalmente tres a cinco niños con infección respiratoria de aquellos que consultaban al servicio de emergencia o de consulta ambulatoria del Hospital. De cada uno de ellos se obtuvo muestras nasofaringeas que fueron examinadas por inmunofluorescencia para virus sincitial respiratorio (VSR), influenza, adenovirus y parainfluenza.

Resultados Se estudiaron 139 niños de los cuales el $40 \%$ fue positivo para alguno de los virus estudiados. El agente viral mas frecuentemente encontrado fue el VSR (27\%), seguido por el virus de la influenza (5\%) y adenovirus (3\%). La circulación de VSR coincidía con los picos de hospitalizaciones por IRA y por neumonía y del hospital, era mas frecuente en los niños menores de 3 años y se encontraba presente durante todo el año.

Conclusiones Los virus respiratorios causan gran parte de la enfermedad respiratoria moderada o severa en el Hosmil y el VSR es el agente más importante entre ellos.

Palabras Clave: Infección, virus, virus sincitial respiratorio, influenza, (fuente: DeCS, BIREME). 


\section{ABSTRACT}

Objective A study was carried out on children seeking medical care at the Hospital Militar (Hosmil) in Bogota due to acute respiratory infection; it was aimed at estimating the frequency of respiratory virus-associated acute respiratory disease (ARD) in children aged under 10.

Methods Three to five children aged less than 10 years old were selected every week from the hospital's emergency ward or ambulatory services over an 18-month period from March 2000 to September 2001. Nasopharyngeal samples were obtained from them and processed using indirect immunofluorescence. The relative frequency of respiratory syncytial virus (RSV), influenza, adenovirus and parainfluenza were calculated.

Results Around $40 \%$ of the 139 children examined proved positive for at least one respiratory virus. RSV was the most frequently found virus (27\% positivity: 38 patients) followed by influenza (5\%: 7 patients) and adenovirus (3\%: 4 patients). RSV circulation peaks coincided with peaks related to ARD and pneumonia in the hospital: it was found most frequently in children aged less than 3 and was present throughout the year.

Conclusion Respiratory viruses were an important cause of moderate to severe respiratory illness in children seeking health care at Hosmil; RSV was the leading agent amongst such viruses.

Key Words: Acute respiratory infection, respiratory syncytial virus, influenza, (source: $\mathrm{MeSH}, \mathrm{NLM})$.

$\mathrm{L}$ as infecciones respiratorias agudas (IRA) del tracto respiratorio inferior son una de las principales causas de mortalidad de niños en el mundo, particularmente en países en desarrollo,causando aproximadamente un tercio de todas las muertes estimadas en niños menores de 5 años $(1,2)$.

Entre los numerosos agentes etiológicos descritos, los virus se reconocen como los agentes predominantes en las IRA, tanto en niños como adultos, ya sea en países en desarrollo o en países industrializados $(1,2)$.

Si bien se postulaba que en países en vías de desarrollo, la etiología bacteriana era la predominante en las IRA, en un estudio multicéntrico internacional coordinado por el Board on Science and Technology for International Development de la National Academy of Sciences de Estados Unidos, se encontró que la etiología viral está presente en mayor proporción que la bacteriana, variando los porcentajes de identificación viral según el país entre 17 y $44 \%$ en niños menores de 5 años. Los virus aislados más frecuentemente fueron el virus sincitial respiratorio (VSR), entre 11 y $37 \%$ del 
REVISTADE SALUD PÚBLICA· Volumen 9 (4), Diciembre 2007

total de los casos estudiados; el adenovirus, entre 1 y $7 \%$, los parainfluenza 1 y 3, entre 1 y 11 \%; y los influenza A y B, entre 1,4 y 4,3 \% (1).

En América Latina, especialmente en los países de la zona intertropical, hay poca información sobre los patógenos que causan la infección respiratoria aguda, especialmente los virales. La mayoría de los estudios disponibles en América Latina han sido realizados en periodos cortos de tiempo y proceden especialmente de las zonas templadas del continente como Argentina, Chile y el sur del Brasil, donde el comportamiento estacional de estos virus puede ser completamente diferente del que se observaría en las zonas mas calidas (3-9).

En Colombia, se ha vigilado la frecuencia de los virus respiratorios en la población desde 1997 hasta la fecha, bajo la coordinación del Centro Control de Enfermedades de la Subdirección de Epidemiología y del Grupo de Virología del Laboratorio Nacional de Referencia del Instituto Nacional de Salud, ha centrando sus objetivos en caracterizar el patrón de circulación de influenza y de otros virus respiratorios como parainfluenza 1,2 y 3 , adenovirus y virus sincitial respiratorio (10).

El presente estudio muestra los resultados de un análisis sobre algunas características epidemiológicas y clínicas de la enfermedad, causada por algunos de los virus respiratorios más comunes, en niños menores de 10 años atendidos en el hospital Militar Central de Bogotá.

\section{METODOLOGÍA}

Se realizo un estudio trasversal que estimó la frecuencia de virus respiratorios en la nasofaringe de niños que consultaron al Hospital Militar Central de Bogotá por enfermedad respiratoria aguda (IRA). El estudio también describió algunas características clínicas y epidemiológicas de los niños positivos o negativos a los virus respiratorios. El Hospital Militar es un hospital de tercer nivel al cual consultan niños de diferentes sectores de Bogota y que tiene un promedio anual de 850 consultas por IRA.

La población de estudio fueron los niños que consultaron al Hospital por IRA y la muestra fue seleccionada entre Marzo de 2000 y Octubre de 2001. Los participantes se seleccionaban un día a la semana, generalmente los martes, de los primeros pacientes que consultaran y que llenaran los siguientes criterios de selección: una edad entre 0 y 10 años, un máximo de 3 días de evolución y que tuvieran al menos dos de los siguientes síntomas: fiebre, tos, dificultad 
respiratoria, dolor de garganta o rinorrea. El número de pacientes seleccionados oscilaba entre 3 y 5 pacientes por día. Las fuentes de información que se consultaron incluian las fichas epidemiológicas utilizadas en la vigilancia de virus respiratorios, las historias clínicas, los registros de consulta externa y de urgencia del hospital y los registros de laboratorio de virología del Instituto Nacional de Salud.

Las variables que se recogieron incluían: el genero, la edad, la procedencia, algunos síntomas (fiebre, tos, rinorrea, odinofagia, cefalea, mialgias, dificultad respiratoria, vomito, otalgia), signos (tirajes, polipnea, cianosis, sibilancias, estertores, aumento de temperatura), diagnostico radiológico (infiltrados intersticiales, consolidaciones, atrapamiento de aire, atelectasia), diagnostico clínico, manejo (ambulatorio, hospitalario), evolución hospitalaria (complicaciones, ingreso a UCI, intubación, patología concomitante), diagnostico virológico, egreso (mejoría, defunción, dependencia de oxigeno).

Las muestras se tomaron con escobillones Voricult @ (MW 950/974/975 Medical Wire Equipment Co. Ltd.) de la pared posterior de la faringe, idealmente dirigida hacia la nasofarínge.

A nivel del laboratorio se realizaron pruebas de inmunofluorescencia indirecta para la detección de los virus de influenza tipo A y B. Además para detección de virus sincitial respiratorio (VSR), adenovirus y parainfluenza tipo 1, 2 y 3, (panel para virus respiratorios referencia 3105 marca Chemicon) (5). El intento de aislamiento viral se realizó utilizando líneas celulares susceptibles como $\mathrm{H}$ 292 para adenovirus y MDCK para virus influenza (6). Para la identificación y tipificación de los virus de influenza tipo A y B y sus respectivos subtipos se efectuó la técnica de inhibición de hemaglutinación (The 2000-2001 Influenza Reagent Kit, WHO) (11).

Los datos de los pacientes y los resultados del laboratorio se digitaron en una base de datos del programa estadístico Epi.info 6.04 (12). Se describió la frecuencia de los virus respiratorios, especialmente virus sincitial respiratorio, con respecto al total de los pacientes observados y para cada uno de los cuadros clínicos descritos en las historia clínicas. Para la descripción de las variables se utilizaron medidas de tendencia central como el promedio, de posición como la mediana, o porcentajes de acuerdo con la escala de medición de las variables de interés. Cuando fue necesario se calcularon intervalos de confianza y las diferencias de proporciones o de promedios fueron evaluadas con pruebas de significancia estadística como Chi cuadrado, test exacto de Fisher o análisis 
REVISTADE SALUD PÚBLICA· Volumen 9 (4), Diciembre 2007

de varianza según el caso. Para todos los intervalos de confianza o pruebas estadísticas el nivel de confianza fue del 95\%.

\section{RESULTADOS}

Se incluyeron 139 niños en los 18 meses de duración del estudio. Todos los pacientes provenían de Bogotá y el 58,3 \% eran de género masculino. El 40 \% (50) fueron positivos para algún tipo de virus, siendo el VSR el que se recuperó mas frecuentemente con $27 \%$ (38 pacientes), seguido por el virus de la influenza con $5 \%$ (7 pacientes) y el adenovirus con $3 \%$ (4 pacientes). EL VSR se identificó en 14 meses de los 18 que duró la vigilancia, mientras que el adenovirus fue detectado en 4 meses y el virus de la influenza en 3 . Se observaron también diferencias para el aislamiento de los virus según la edad ya que el VSR predominó en los niños menores de 3 años ( $97 \%$ de los aislamientos) mientras que el virus de influenza se presento en niños de más edad (57 \% de los aislamientos en mayores de 3 años). La distribución completa de los virus aislados por grupo de edad se muestra en la Tabla 1.

Tabla 1.Distribución por edad de los virus respiratorios identificados en los niños que consultaron al Hospital Militar Central, Bogota. Marzo 2000-Octubre 2001

\begin{tabular}{|c|c|c|c|c|c|c|c|c|c|c|c|c|c|c|}
\hline $\begin{array}{l}\text { Edad } \\
\text { Arīos }\end{array}$ & \multicolumn{2}{|c|}{ VSR } & \multicolumn{2}{|c|}{ Influerza } & \multicolumn{2}{|c|}{$\begin{array}{l}\text { Adeno } \\
\text { vinus }\end{array}$} & \multicolumn{2}{|c|}{$\begin{array}{c}\text { Para } \\
\text { infuenza } 1\end{array}$} & \multicolumn{2}{|c|}{ Negalivos } & \multicolumn{2}{|c|}{$\begin{array}{c}\text { "No } \\
\text { Reportados }\end{array}$} & \multicolumn{2}{|c|}{ Tdal } \\
\hline & $n$ & $\%$ & $\mathrm{n}$ & $\%$ & $\mathrm{n}$ & $\%$ & $\mathrm{~N}$ & $\%$ & $\mathrm{~N}$ & $\%$ & $\mathrm{n}$ & $\%$ & $n$ & $\%$ \\
\hline$<1$ & 25 & 325 & 1 & 1.3 & 2 & 26 & 1 & 1.3 & 43 & 58 & 5 & 6.5 & 77 & 56.4 \\
\hline $1-3$ & 12 & 29.3 & 2 & 4.9 & 2 & 49 & 0 & 0 & 21 & 51.2 & 4 & 97 & 41 & 29.4 \\
\hline $4-6$ & 1 & 7.1 & 3 & 21.4 & 0 & 0 & 0 & 0 & 7 & 50 & 3 & 21.4 & 14 & 10 \\
\hline $7-10$ & 0 & 0 & 1 & 16.7 & 0 & 0 & 0 & 0 & 4 & 66.6 & 1 & 16.7 & 6 & 4.4 \\
\hline Tdal & 38 & 27.3 & 7 & 5 & 4 & 29 & 1 & 0.72 & 75 & 53.9 & 14 & 10 & 138 & 100 \\
\hline
\end{tabular}

En los 18 meses de seguimiento se presentaron dos picos de circulación de virus respiratorios que coincidieron con los meses de marzo a junio, siendo el mes de mayo el de mayor circulación viral para los dos años (2000 y 2001).

La neumonía fue el diagnostico clínico mas frecuente seguido por la bronquiolitis y la infección respiratoria aguda (IRA) alta. El VSR causo el 34,5 $\%$ (20 casos) de las neumonías, el 20,4 \% (10 casos) de las IRA altas y el 30,8 \% (8 casos) de las bronquiolitis. El virus de influenza se presentó en el 8,2 \% (4 casos) de las IRA altas, en el 7,7 \% (2 casos) de las bronquiolitis y el 2 \% (1 caso) en las crisis asmáticas. Entre abril y junio del año 2001 se incrementaron las hospitalizaciones por diagnostico por neumonía y bronquiolitis con una disminución total en el mes de julio coincidiendo con la dinámica de circulación viral que se registro para este mismo periodo en los niños que hicieron parte de la vigilancia de virus respiratorios (Figuras 1 y 2). 
Figura 1. Porcentaje de identificación viral y total de hospitalizaciones por neumonía Hospital Militar. Enero-Septiembre 2001

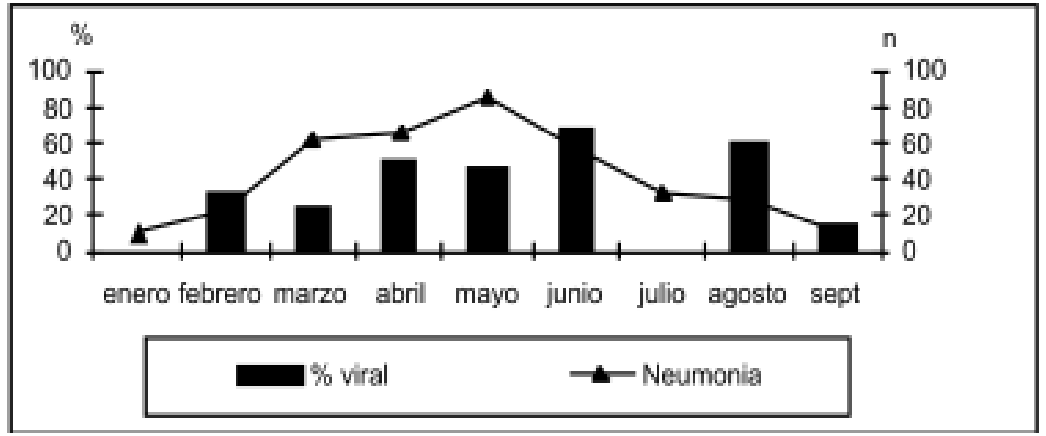

Figura 2. Porcentaje de identificación viral y total de hospitalizaciones por Bronquiolitis Hospital Militar. Enero-Septiembre 2001

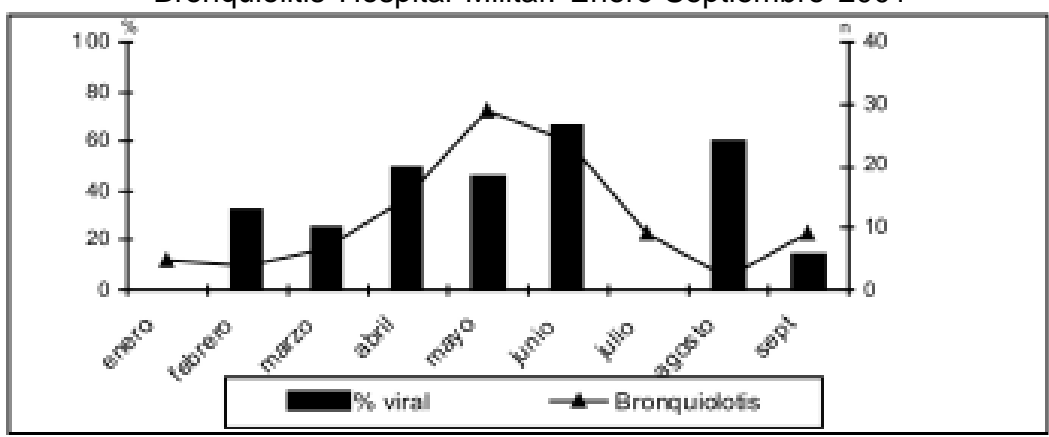

Los síntomas mas frecuentes en los pacientes que se incluyeron en el estudio fueron: tos 124 (89,2 \%), fiebre 98 (70,5\%), dificultad respiratoria 80 (57,5\%) y rinorrea 79 (56,8 \%). No se presentó ninguna diferencia en la proporción de síntomas entre los pacientes con diagnóstico positivo para virus de influenza o VSR comparado con los negativos.

El 25,6 \% de los niños estudiados (36 casos) fueron hospitalizados; la gran mayoría de ellos eran menores de un año y de sexo masculino (83,4 \% y 64 \% respectivamente). El agente viral mas frecuente entre los niños hospitalizados fue el virus sincitial respiratorio con 14 casos (39 \%) seguido por el virus de influenza con un caso (3\%). La proporción de hospitalizaciones en los niños con VSR fue de $37 \%$ (14/38) mientras que entre los niños con virus influenza fue 14 $\%$ (1/7) y entre los pacientes con diagnostico negativo para virus la proporción de hospitalización fue de 28 \% (21/75). Ninguna de las diferencias en porcentajes de hospitalizados fue estadísticamente significativa. 
REVISTADE SALUD PÚBLICA· Volumen 9 (4), Diciembre 2007

Entre los niños hospitalizados el diagnóstico más frecuente fue neumonía con 29/36 casos (80,5 \%), y el agente etiológico mas frecuente en ese diagnostico fue el VSR con 41 \% (12/29). En las bronquiolitis 2 de 5 hospitalizados también presentaron VSR. Debe resaltarse que el $59 \%$ de los niños que se hospitalizaron con neumonía fueron negativos para virus respiratorios (Tabla 2).

Tabla 2. Diagnostico clínico y etiología viral, en niños que consultaron y fueron hospitalizados en el hospital Militar Central. Bogotá, marzo 2000 - octubre 2001

\begin{tabular}{lcccccc}
\hline \multicolumn{1}{c}{ Diagnóstico } & \multicolumn{2}{c}{ VSR } & \multicolumn{2}{c}{ Irfluenza } & \multicolumn{2}{c}{ Negativo } \\
& $\mathrm{n}$ & $\%$ & $\mathrm{n}$ & $\%$ & $\mathrm{n}$ & $\%$ \\
\hline Neumonia & 20 & 52.7 & 0 & 0 & 37 & 52.2 \\
IRA alta & 10 & 26.3 & 4 & 66.7 & 24 & 33.8 \\
Bronquiolitis & 8 & 21 & 2 & 33.3 & 10 & 14 \\
Total & 38 & 100 & 6 & 100 & 71 & 100 \\
Pacientes hospitalizados & & & & & & \\
Neumonia & 12 & 85.7 & 0 & 0 & 17 & 81 \\
IRA alta & 0 & 0 & 1 & 100 & 1 & 4.8 \\
Bronquiolitis & 2 & 14.3 & 0 & 0 & 3 & 14.2 \\
Total & 14 & 100 & 1 & 100 & 21 & 100 \\
\hline
\end{tabular}

Se compararon algunos signos clínicos de severidad de la enfermedad entre los pacientes con VSR y los pacientes negativos para todos los virus. No se observaron diferencias estadísticamente significativas con respecto a la frecuencia de signos como estertores, tirajes, sibilancias, polipnea o aumento de temperatura entre los dos grupos. Tampoco se observaron diferencias estadísticamente significativas por síntomas.

El promedio de días hospitalización fue de 7,7 días y era similar para los positivos a VSR y los negativos a todos los virus respiratorios. El rango de hospitalización estuvo entre 1 y 29 días para los negativos y entre 1 y 17 días para los niños con VSR.

Seis de los 36 pacientes hospitalizados (16,7 \%) presentaron alguna complicación y dos de ellos (5,5 \%) eran positivos para VSR. Estos últimos tenían un diagnostico clínico de neumonía y presentaron falla respiratoria y sobre infección bacteriana. El tiempo de hospitalización fue de 14 y 17 días respectivamente. Solo uno recibió tratamiento antimicrobiano (Claritromicina).

\section{DISCUSIÓN}

El presente estudio sugiere que un porcentaje importante de las infecciones respiratorias que ocurren en menores de 10 años y que ameritan atención en hospitales de tercer nivel en Colombia son causadas por virus respiratorios. 
Entre estos agentes se destaca la frecuencia del VSR, quien se muestra como el agente singular que más se asocia con la enfermedad respiratoria severa 0 moderada superando entre 7 y 5 veces a los otros agentes virales. No solamente el VSR es mas frecuente, sino que también se asocia mas frecuentemente a enfermedad respiratoria baja que tiende a ser más severa como neumonía y bronquiolitis. Los casos asociados con VSR necesitaron manejo hospitalario en mayor proporción que los otros con un promedio de estancia superior a una semana, lo que sugiere que tenían un cuadro clínico más severo. Estos resultados son similares a los descritos en otros estudios, donde el VSR se ha detectado más frecuentemente en menores de un año y se asocia predominantemente a bronquiolitis y neumonías. Howard y colaboradores encontraron, usando una muestra de los egresos de Estados Unidos entre 1993 y 1995, que la enfermedad por RSV representaba entre 300 y 400 millones de dólares en costos hospitalarios, lo cual confirma la complejidad clinica que impone el manejo adecuado de los pacientes con infecciones por este germen $(1,2,11,13-15)$.

En la población del Hospital Militar de Bogotá, los virus respiratorios fueron identificados durante casi todos los meses del año excepto en enero y julio, con el mayor pico de ocurrencia en abril, junio y agosto. De manera interesante, el pico de circulación viral coincide, en nuestra serie, con el aumento de consultas por enfermedad respiratoria y con el pico de hospitalizaciones por neumonías y bronquiolitis, especialmente en los meses de abril a junio. Debido a lo corto de la serie no se utilizaron metodos estradisticos especificos para relacionar la ocurrencia de virus con el aumento de consultas pero esto es un fenomeno descrito en otros estudios. En los países templados del hemisferio norte, el VSR y el virus de la influenza generalmente circulan entre Septiembre y Abril y su circulación dura entre 3 y seis meses, adicionalmente se ha demostrado en estas áreas que el pico de circulación de virus coincide con un mayor numero de episodios de enfermedad por Streptococcus pneumoniae. Datos de la vigilancia para virus respiratorios que el Instituto Nacional de Salud lidera desde 1997 muestran que el VSR también puede circular todo el año en otras poblaciones $(9,16)$.

Una de las fortalezas de este estudio fue la alta tasa de recuperación viral, de $40 \%$, sin necesidad de utilizar métodos especiales de identificación, lo que sugiere una buena selección de los pacientes y que las muestras fueron tomadas en el período de tiempo adecuado. En otros estudios el porcentaje de identificación viral fluctúa entre 10 \% y 50 \% dependiendo del tipo de población donde se realiza el estudio y de los métodos empleados $(6-8,11,13)$. 
REVISTADE SALUD PÚBLICA• Volumen 9 (4), Diciembre 2007

Las debilidades del presente estudio estuvieron principalmente en no haber realizado paralelamente una correlación entre la infección viral y bacteriana en los mismos pacientes por lo que no nos es posible saber si ese aumento se debe todo a la presencia de los virus o si también coincidía con un aumento de enfermedad por agentes bacterianos $(2,16)$. Adicionalmente, el número relativamente pequeño de pacientes no permitio hacer comparaciones adecuadas la IRA baja viral y la no viral. Aunque no se encontraron diferencias en los signos o síntomas clínicos entre los pacientes con diagnostico de virus positivo y los negativos, el porcentaje de hospitalizaciones tendía a ser mayor en los pacientes positivos para VSR que en los negativos, sugiriendo un cuadro menos severo en los negativos, diferencia que no pudo ser confirmada por esa falta de poder estadístico. Otros estudios, sin embargo, han mostrado que la enfermedad respiratoria por VSR puede ser mas severa que por agentes no virales especialmente en menores de 1 año $(5,17)$.

El diagnostico de los virus respiratorios por laboratorio es importante por lo que se deberían implementar técnicas diagnosticas para ello en los hospitales donde hay servicio de pediatría, ya que se podría dar un mejor manejo a los pacientes con infección respiratoria evitando el uso indiscriminado de tratamiento antimicrobiano y con ello bajando el costo de las hospitalizaciones. Alvis y colaboradores han calculado que los costos directos de una neumonía presuntamente viral en Colombia están entre 273 y 550 dólares americanos de 2002 y que los antibióticos pueden contribuir hasta con el 10\% de esos costos directos $(14,18)$.

Teniendo en cuenta que el VSR es el virus predominante en las infecciones respiratorias en menores y que no solo se transmite por vía aérea sino también a través de manos u objetos contaminados o por secreciones infectadas, en los hospitales con servicio de pediatría se deben implementar las medidas adecuadas para prevenir su transmisión nosocomial (19)

Agradecimientos. Al Influenza Branch del Centro para el Control y Prevencion de Enfermedades (CDC) quienes apoyaron al laboratorio de Virologia del Instituto Nacional de Salud (INS) para reasumir la vigilancia de virus respiratorios desde 1997. A Sanofi-Pasteur que han apoyado algunas de las actividades de Vigilancia del laboratorio de virologia del INS. Al Ministerio de la Proteccion Social que proveyo apoyo financiero parcial para el fortalecimiento del laboratorio de influenza en el INS. 


\section{REFERENCIAS}

1. Benguigui Y, López F, Schmunis G, Yunes J. Infecciones respiratorias en niños. Organización Panamericana de la Salud, Washington, D.C.: 1997.

2. Van Woensel J, Van Aalderen W, Kimpen J. Viral lower respiratory tract infection in infants and young children. BMJ 2003; 327:36-40.

3. D Arce J, Moncada R, Mardones R, Velozo L, Parra G. Secuelas post-infección por adenovirus en niños: Evaluacion con tomografía computada. Revista Chilena de Radiología 2002; 8(4):154-163.

4. Bueno G, Teper A, Colom A. Acute viral bronchiolitis and its sequelae in developing countries. Pediatric Respiratory Reviews 2002; 3: 298-302.

5. Savy V, Baumeister E, Boir F, Shiroma M, Campos A. Evaluación etiológica y clínica de infecciones respiratorias agudas bajas en una población infantil. Medicina (Buenos Aires) 1996; 56 (3). 213- 217.

6. Straliotto S, Siquiera M, Muller R, Fischer G, Cunha M, Nestor S. Viral etiology of acute respiratory infections among children in Porto Alegre, RS, Brazil. Revista da Sociedade Brasileira de Medicina Tropical 2002; 35(4):283-291.

7. Moura E, Borges L, Souza L, Ribeiro D, Siqueira M, Ramos E. Estudo de infeccoes respiratorias agudas virais em criamcas atendidas en um centro pediatrico em Salvador (BA). Jornal Brasileiro de Patología e Medicina Laboratorial 2003; 39 (4):275-282.

8. Celadilla M, Winocur D, Cohen A, Nejamkis M, Carballal G. Virus Sincitial Respiratorio en menores de cinco años hospitalizados. Infectología y Microbiología Clínica 1992; 4:31-5.

9. Pumariega T, Savón C, Muné M, Cancio R, González G, Valdivia A, et al. Isolation and identification of adenovirus in hospitalised children under five years, with acute respiratory disease, in Havana, Cuba. Mem Inst Oswaldo Cruz 2000; 95 (6):859861.

10. Herrera D, de la Hoz F, Mariño C, López J, Vélez C, Arboleda L. Vigilancia de influenza y virus respiratorios en Colombia enero de 2000 a 31 de julio de 2001. Informe Quincenal Epidemiológico Nacional 2001; 6(17): 267-72

11. Name O, Acevedo M, Boshell J. Estudio clínico epidemiológico de las virosis respiratorias bajas en lactantes. Hosmil Medica. 1987; 8 (2) : 62-7

12. Dean AG, Dean JA, Coulombier D. Epi Info, version 6: a word prosessing, database, and statistics program for public health on IBM compatible microcomputers. Atlanta, Georgia, U.S.A: Centers for Disease Control and Prevention; 1995.

13. Carballal G, Oubiña J. Virología Médica.1a edición. Editorial El Ateneo: Buenos Aires; 1991.

14. Zeinat H, Pacsa A, Eisa S, El Shazli A, El-Salam RA. Laboratory Diagnosis of Acute Lower Respiratory Tract Viral Infections in Children, Journal of Tropical Pediatrics 1996; 42(5):276-280. 
REVISTADE SALUD PÚBLICA· Volumen 9 (4), Diciembre 2007

15. Howard T, Hoffman L, Stang P, Simoes E. Respiratory sincitial virus pneumonia in the hospital setting: length of stay, charges and mortality. J Pediatr 2000: 137: 227-32.

16. Talbot T, Poehling K, Hartert T. Seasonality of invasive pneumococcal disease: Temporal relation to documented influenza and respiratory syncitial viral circulation. The American Journal of Medicine 2005; 118: 285-91.

17. Horwitz M. Adenoviral diseases. In: Virology, Fields BN, Melnick JL (Eds.), New York: Rave Press; 1985. pp 477-495.

18. Alvis N, de la Hoz F, Higuera A, Pastor D, Di Fabio J. Costos económicos de las neumonías en niños menores de dos años en Colombia. Revista Panamericana de Salud Publica 2005; 17 (3):178-83.

19. Weber M, Mulholland K, Greewood B. Respiratory syncytial virus infection in tropical and developing country. Tropical Medicine and International Health 1998; 3 (4): 268-280. 